\title{
ЕВРОПЕЙСКАЯ КОМИССИЯ ПО ЭФФЕКТИВНОСТИ ПРАВОСУДИЯ - КОНСУЛЬТАТИВНЫЙ ОРГАН СОВЕТА ЕВРОПЫ, РАЗРАБАТЫВАЮЩИЙ И ОБЕСПЕЧИВАЮЩИЙ ПРИМЕНЕНИЕ РЕКОМЕНДАЦИЙ В СФЕРЕ ОТПРАВЛЕНИЯ ПРАВОСУДИЯ
} иели создания, природа и организачионные основы Европейской комиссии по эффективности правосудия Совета Европьы. Исследуются вопросы функиионирования Комиссии; ее внутренние органы и структуры. Рассматриваются нормативные правовые акты Совета Европь. Исследуются отдельные аспекты функиионирования Комиссии. Описывается взаимодействие Комиссии с другими органами Совета Европы, атакже сгосударствами-членами Совета Европь. Автор делает упор на аналитическоми иекомендательномхарактере большинства функций Комиссии. Автор отмечает, что Комиссия наделена аналитическими ирекомендательными функциями, которые она осуществляет во взаимодействии с другими органами власти Совета Европы. В тоже время это взаимодействие осуществляется во взаимодействии сгосударствами-членами Совета Европь. Анализируются отдельныедокументы Совета Европь и Комиссии в частности, а также результаты деятельности Комиссии. Также отмечается, что основной функция Комиссии заключается в содействии имплементачии европейских стандартов, касающихся правосудия, в правопорядки государств-членов.

Abstract: This article presents the functions of the European Commission for the Efficiency of Justice, its purpose, nature and organizational foundations. The mechanism of functioning of the Commission and its structure are being researched. The normative legal acts of the Council of Europe are being reviewed in the article. The author examines certain aspects of functioning of the Commission, as well as describes its cooperation with other branches of the Council of Europe and member states of the Council of the Council of Europe. The author emphasizes that the Commission possesses the analytical and recommendation functions that are used in the cooperation with other member states of the Council of Europe. Separate documents on the Council of Europe and the Commission in particular, along with the results of their work are being analyzed. The author also notes that the key function of the Commission consists in the assistance of implementation of the European standards pertaining to the justice and law enforcement of the member countries.

Ключевые слова: Эффективность правосудия, Совет Европь, европейская комиссия, взаимодействие, европейские стандарты, органь Совета Европы, судебная практика, права человека, консультативная деятельность, международное право.

Keywords: Efficiency for the justice, Council of Europe, European Commission, correlation, European standards, branches of the Council of Europe, court rulings, human rights, consultative activity, international law.

1. Сущность и организационные основы Европейской комиссии по эффективности правосудия

вропейская комиссия по эффективности правосудия (Commission européenne pour l'efficacité de la justice) (далее-ЕКЭП или комиссия) является аналитическим и консультативным институтом Совета Европы, в функции которого входит оказание помощи государствам-членам Совета Европы по совершенствованию их систем правосудия. Создание данного института[1] преследовало цель улучшения качества правосудия государств-членов Совета Европы, доведения их систем правосудия до стандартов и норм Совета Европы. Речь, в первую очередь, идет о деятельности по приведению в соответствие судебных систем государств-членов с требованиями к качеству отправления правосудия, установленными ст. 5, 6, 13 и 14 Европейской конвенции по правам человека (далее ЕКПЧ), которые касаются именно качественного разрешения правовых споров в рамках внутригосударственных систем правосудия. Иначе говоря, ЕКЭП является одним из профильных институтов (так как ее деятельность огранивается вопросами отправления правосудия в государствах-членах), который обладает функциями аналитического и консультативного органа и способствует имплементации требований конвенционного права Совета Европы и судебной практики Европейского суда по правам человека (далее: ЕСПЧ), касающихся качества систем правосудия.
Отчасти создание данного органа Совета Европы было обусловлено, по словам самого Президента ЕКЭП[2], чрезмерной загруженностью исками ЕСПЧ, а сокращение нагрузки на последнего, по идее создателей комиссии, должно было быть осуществлено посредством повышения качества функционирования судебных систем государств-членов и смещения, таким образом, нагрузки по рассмотрению судебных споров с наднационального на национальный уровень. Если принять во внимание тот факт, что большинство дел, рассматриваемых ЕСПЧ, касается именно нарушений прав человека судебными органами - а именно нарушений гарантий судебной защиты, закрепленных ст. 6 ЕКПЧ, - то актуальность создания комиссии становится очевидной.

Таким образом, деятельность комиссии объединяет два основных направления деятельности Совета Европы, которые в соответствии с Уставом организации[3] касаются основных прав и свобод граждан, а именно прав граждан, которые обеспечиваются непосредственно системами правосудия государств-членов, а также верховенства права, которое обеспечивается органами правоприменения, конечным из которых являются именно органы правосудия. Достижение данных целей осуществляется в том числе за счет улучшения качества работы судебных систем государств-членов, что реализуется в рамках Совета Европы за счет аналитической, экспертной и консультативной деятельности ЕКЭП. 
Деятельность ЕКЭП можно охарактеризовать не как рекомендательную, а как аналитическую. Действительно, если рассматривать основной вид деятельности комиссии, он заключается в подготовке докладов о европейских судебных системах, а также оценке качества судебных систем европейских государств, из чего становится очевидным, что его основная деятельность заключается в оценке (assessment) различных аспектов функционирования судебных систем на основе статистических данных, а не предоставлении рекомендаций государствам-членам в отношении эффективности функционирования их судебных систем. Конечно же, положительная или отрицательная оценка Комиссии о том или ином аспекте функционирования судебных систем носит рекомендательный характер, но скорее является второстепенным по отношению к аналитической или даже исследовательской функции данного органа Совета Европы. Таким образом, деятельность комиссии является менее инвазивной с точки зрения международного права и международной политики, чем деятельность других органов Совета Европы, что объясняет меньшую осведомленность общественности и специалистов международного права о ее деятельности и объясняет актуальность данной работы.

Будучи одним из многочисленных институтов Совета Европы[4], ЕКЭП является одной из структур, которая взаимодействует с другими органами Совета Европы при содействии Департамента правового и судебного сотрудничества Совета Европы (Justice and Legal Cooperation Department), а также Европейского комитета по правовому сотрудничеству (European Committee on Legal Co-operation). Среди профильных структур Совета Европы, которые непосредственно сотрудничают с ЕКЭП ввиду их профильной специальности, которая также направлена на решение вопросов улучшения качества национального правосудия, можно назвать: Консультативный совет европейских судей (Consultative Council of European Judges), Консультативный совет европейских прокуроров (Consultative Council of European Prosecutors).

В сравнении с ЕКЭП последние отличаются своим членским составом, а также специфичностью их компетенции. Действительно, в отличие от ЕКЭП их деятельность направлена не на вопросы повышения качества функционирования национальных судебных систем в целом, а на соответствующие их профильной ориентации вопросы: вопросы статуса судей в компетенции Консультативного совета европейских судей, а вопросы статуса прокуроров в компетенции Консультативного совета европейских прокуроров.

Устав ЕКЭП однозначно свидетельствует о вспомогательном характере данного института в рамках Совета Европы, деятельность которого направлена на содействие основным органам Совета Европы. Так, в частности уточняется, что ЕКЭП «формулирует консультативные заключения по запросам:

- Парламентской Ассамблеи Совета Европы (далее ПАСЕ),

- Европейского суда по правам человека,

- комитетов Совета Европы,

- Европейского комитета по правовому сотрудничеству (European Committee on Legal Co-operation),

- Европейского комитета по уголовным проблемам (European Committee on Crime Problems),
- Комитета по правам человека (Steering Committee for Human Rights),

- К Консультативного совета европейских судей (Consultative Council of European Judges) и

- Генерального секретаря.

Более того, в соответствии с Уставом комиссии (п. 3 ст. 5) в ее состав входят представители Президента ПАСЕ и Президента ЕСПЧ, а также представители других отдельных комитетов Совета Европы (в первую очередь, Европейского комитета по правовому сотрудничеству)[5].

Стоит отметить, что данный институт так и не получил нормативной и распорядительной компетенции, подобной тем, которые существуют у таких органов Совета Европы, как, например, Комитет министров или Парламентская ассамблея, что вполне логично, так как изначально он является вспомогательным органом Совета Европы, о чем свидетельствует п. 2 ст. 2 его Устава, который гласит: «ЕКЭП не является механизмом мониторинга и наблюдения за реализацией государствами обязательств». Бывший сотрудник Совета Европы Роберто Лампони как нельзя более точно выразил сущность данного института: «ЕКЭП является действительно интересным институтом, так как она не обладает нормативной властью, а скорее ограничивается организацией помощи государствам в применении уже существующих норм»[6].

ЕКЭП создана на паритетной основе (по одному эксперту от каждого государства (ст. 5 Устава)), представлены все (47) члены Совета Европы, что обеспечивает его репрезентативность и авторитет, так как в лице представителей различных государств учитываются мнения различных государств-членов. Это особенно важно, так как в рамках своей деятельности Комиссия призвана формулировать рекомендации для государств-членов по совершенствованию их судебных систем в свете обязательств ЕКПЧ. Более того, если принять во внимание тот факт, что Комиссии приходится организовывать встречи с представителями судебных систем государств-членов; организовывать работу по содействию органов государств в реформировании их судебных систем и оценке качества их деятельности, то становится очевидным, что состав данного органа имеет первостепенную важность.

Интересным является и тот факт, что в работе данного института принимают участие в качестве наблюдателей и представители государств, не являющихся членами Совета Европы. Речь, в частности, идет о представителях Израиля, Канады, Мексики, США, Ватикана, Марокко и Японии. Комиссия также сотрудничает с международными неправительственными организациями и даже с органами Европейского Союза (Советом Европейского Союза и Европейской Комиссией). Именно сотрудничество с органами последнего вызывает наибольший интерес, так как присоединение Европейского Союза, анонсированное Протоколом № 14, к ЕКПЧ, приведет к необходимости сотрудничества органов двух региональных объединений (и, в первую очередь, судебных органов). Как следствие, Европейскому Союзу придется учитывать судебную практику ЕСПЧ, в том числе и касающуюся судебных систем и процессуальных гарантий, установленных ст. 5, 6, 13 и 14 ЕКПЧ. Принимая во внимание тот факт, что Комиссии по эффективности правосудия приходится ежедневно анализировать применимость этих принципов в судебных системах государств-членов, то обращение органов Европейского Союза за консультациями по данным 
DOI: $10.7256 / 1811-9018.2014 .12 .14004$

При цитировании этой статьи сноска на dоі обязательна

\section{Право и политика $12(180) \cdot 2014$}

вопросам к Комиссии должно стать естественным, а участие представителей ЕС в работе данного органа обязательным.

Комиссия функционирует на основе внутреннего документа[7], разработанного ей по собственной инициативе, что свидетельствует о наличии у данного органа определенной функциональной автономии. Данный акт, в частности, уточняет, что к ЕКЭП применяются правила Резолюции 76(3), касающейся деятельности комитетов Совета Европы, что свидетельствует о том, что правовые данного института сравнимы с теми, которые присущи рабочим органам этой международной организации.

ЕКЭП избирает из числа своих членов президента и вице-президента (ст. 2 Регламента ЕКЭП), что также свидетельствует о наличии функциональной автономии данного органа. Более того, избрание на данные должности проходит достаточно либерально, так как в отступление от повсеместно применяемых в международном праве правил о единогласии, избрание руководства ЕКЭП осуществляется на основе большинства (п. 3 ст. 2 Регламента)[8]. Комиссия также обладает и такой институциональной структурой, как Бюро (Bureau), которое наделено административно распорядительными функциями (ст. 3):

- $\quad$ координацией деятельности рабочих групп комиссии;

- $\quad$ распределением работы между членами комиссии;

- $\quad$ обладает правом предлагать кандидатов на должности экспертов,

- исполнять другие функции, возлагаемые комиссией.

Из числа членов Комиссии формируются рабочие группы (ст. 6 Регламента), которые реализуют конкретные действия по разработке официальных документов данного органа. Рабочие группы являются профильными:

- Рабочая группа по оценке судебных систем (Working Group on the evaluation of judicial systems);

- $\quad$ Рабочая группа по качеству судебных систем (The Working Group on quality of justice);

- Ц Центр управлению сроками в судопроизводстве (Centre for judicial time management) или Исследовательская сеть по анализу и изучению использования времени в судопроизводстве (Study and Analysis of judicial Time Use Research Network (Далее: SATURN или CATУPH)

- Рабочая группа по исполнению судебных решений (The Working Group on execution);

- $\quad$ Рабочая группа по медиации (Working Group on mediation). Стоит отметить, что работа между данными структурами ЕКЭП распределяется неравномерно, так как две первых являются широкопрофильными, а остальные узкопрофильными. В то же время существует противоречие с том, что каждая из рабочих групп состоит их одинакового количества членов (экспертов) ЕКЭП. Как следствие, на практике рабочая нагрузка, возложенная на Комиссию, распределятся между рабочими группами неравномерно, а рабочим группам по оценке судебных систем и качеству судебных систем в будущем придется прибегать к внешней извне.

\section{2. Функции Европейской комиссии по эффективности правосудия}

Как уже было сказано выше деятельность ЕКЭП рекомендательный или даже аналитический характер, но одновременно распространяется как на органы Совета Европы, так и на государства-члены этой организации. Так, в соответствии с учредительным актом ЕКЭП[9] в компетенцию данного института входят следующие функции:

- $\quad$ анализ судебных систем на их соответствия требованиям и стандартам Совета Европы;

- $\quad$ исследование проблем судебных систем предложение путей их совершенствованию;

- организация обмена информацией, касающейся судебных систем;

- $\quad$ предоставление юридической помощи государствам членам;

- $\quad$ оказание содействия другим профильным комитетам Совета Европы в рамках их нормотворческой деятельности по подготовке международных актов Совета Европы в сфере правосудия (в частности, сотрудничество с Европейским комитетом по правовому сотрудничеству) (ст. 2).

Со временем аналитические и рекомендательные функции ЕКЭП в сфере отправления правосудия получили новое развитие. В соответствии с Планом действий (Action plan), принятом на саммите глав государств и правительств в Варшаве 16-17 мая в 2005 г. было предложено расширить функций данной комиссии. Действительно, данный План действий показал намерения глав государств «...развивать функции анализа (оценки) и содействия Европейской комиссии по эффективности правосудия, а также правильно использовать мнения Консультативного совета европейских судей с целью содействия государствам-членам в обеспечении справедливого и своевременного отправления правосудия, а также с целью развития альтернативных способов разрешения споров...»[10]. Тем не менее в результате принятия данного акта основные функции ЕКЭП так и не изменились. Изменения появились лишь на внутриорганизационном уровне и выразились, в частности, в развитии правового регулирования аналитической деятельности ЕКЭП, которая привела к усилению функций оценки судебных систем государств[11].

Содействие государствам - членам Совета Европы в совершенствовании их систем правосудия является одной из основных функций ЕКЭП. Об этом свидетельствует такой акт комиссии, как Регламент ее деятельности, где данному виду ее деятельности посвящена отдельная глава. Действительно, гл. 2-ая данного текста довольно подробно описывает деятельность комиссии по содействию государствам-членам. Так, например, Регламент уточняет, что деятельность комиссии в отношении того или иного государства-члена может быть инициирована соответствующим государством-членом и осуществляется на основе взаимной правовой помощи (ст. 8). Группы, состоящие из членов комиссии (экспертов), в деятельность которых будет вменена та или иная миссия по оказанию правовой помощи отдельному государству, формируются по инициативе Бюро комиссии.

Деятельность рабочих групп в отношении государства осуществляется в рамках экспертных визитов, в ходе которых члены экспертной группы выезжают на место в соответствующее государство с целью уточнения сведений, необходимых для реализации правовой помощи государству на месте (ст. 10 Регламента). На месте организуется взаимодействие с органами власти государства, а все действия рабочей группы проводятся с разрешения последнего. Окончательные документы 
рабочей группы в отношении того или иного государства подлежат обсуждению в секретариате комиссии, который по результатам данной работы формирует доклад (п. 5 и 6 ст. 10).

Помимо того, что деятельность Комиссии включает в себя анализ статистических данных и законодательных актов государств-членов, касающихся судебных систем, что за время ее деятельности выразилось в принятии ряда докладов о состоянии судебных систем государств-членов, данный институт Совета Европы может предоставить помощь тому или иному государству и по инициативе последнего (ст. 4 уже цитированной нами резолюции).

Комиссия также непосредственно взаимодействует с органами Совета Европы, и в частности, рекомендует им, в случае необходимости, разработать и принять тот или иной юридический нормативный акт, способствующий развитию судебных систем государств-членов. Таким образом, деятельность Комиссии не ограничивается сбором информации, касающейся судебных систем государств-членов, ее анализом, оказанием помощи государствам-членам (в частности юридической), но и характеризуется активной работой с органами самого Совета Европы.

В соответствии вышеупомянутой резолюцией Комитета министров (2002) № 12 о создании ЕКЭП от 18 июля 2002 г. ее деятельность направлена на реализацию в рамках внутренних правопорядков государств-членов обязательств ЕКПЧ, касающихся функционирования судебных систем (см. преамбулу), а именно статей 5,6 , 13 и 14 ЕКПЧ, статей протоколов, касающихся доступа к правосудию; эффективности судебных процедур; исполнения судебных решений; статуса и роли судей, прокуроров, адвокатов и других участников судебной системы; а также управления судебной системой и внедрения в ее деятельность современных коммуникационных технологий. На практике основным направлением деятельности Комиссии стало издание докладов о состоянии судебных систем государств-членов. Сегодня они выходят на регулярной основе[13], суммируют огромное количество статистического материала, обладают аналитической ценностью и являются довольно объемными, что свидетельствует о том, что их авторитет будет только возрастать. Данные доклады, касаются всех государств-членов Совета Европы и базируются на данных, собираемых национальными представителями (корреспондентами) на местах (в государствах-членах). Это позволяет создать полноценную картину о судебных системах государств-членов на основе единых критериев и представить недостатки/преимущества каждой из них на основе сравнительного анализа.

Другим направлением сотрудничества Комиссии и государств-членов стали доклады, подготовленные по запросу одной или нескольких стран. Так, например, Комиссией был проведен анализ политики и процедур назначения судей в Республике Азербайджан[14], тогда как в отношении Российской Федерации уже было представлено несколько докладов, касающихся, в частности, наиболее наболевшей проблемы российского правосудия - исполнения судебных решений[15].

Нельзя не обратить внимание на еще одно направление деятельности Комиссии, которое заключается в издании так называемых «рекомендаций» (Lignes directrices). Речь идет о консультативных и рамочных документах, которые разрабатываются с целью предоставления государствам рекомендаций для осуществления соответствующих реформ их судебных систем. Так, например, одной из последних рекомендаций Комиссии стал документ о территориальном размещении судебных органов государств-членов, направленный на обеспечение доступности услуг органов правосудия и улучшения качества данных услуг[16].

Также в Резолюции Комитета министров (2002) № 12 о создании Комиссии утверждается, что ее деятельность направлена на организацию сотрудничества между государствами-членами (см. преамбулу), хотя ее деятельность касается в большей мере опосредованного сотрудничества как Совета Европы в целом, так и ЕСПЧ в частности с судебными органами государств-членов. Действительно, если принять во внимание, что анализ и оценка функционирования судебных систем государств-членов основывается на базе принципов, установленных ЕКПЧ, а последние получили свое конкретное раскрытие именно в судебной практике ЕСПЧ, то становится очевидным, что конечными критериями качества судебной системы того или иного государства являются интерпретации положений Конвенции, данные этим наднациональным судебным органом. Иначе говоря, рекомендации по совершенствованию судебных систем, которые приходится формулировать Комиссии в рамках своей деятельности, основаны на содержании положений ЕКПЧ и разъяснений их содержания, данных ЕСПЧ, тогда как вся деятельность Комиссии направлена на совершенствование судебных систем государств-членов. Данное утверждение уже подтверждалось и первым президентом ЕКЭП Эберхартом Дэшем (Eberhard Desch), который, в частности, утверждал, что создание данного органа преследовало цель обеспечения гарантии соблюдения европейских стандартов в сфере правосудия[17].

Более того, данное умозаключение подтверждается и самими положениями резолюции о создании Комиссии. Так, преамбула резолюции, рассматривая цели создания Комиссии, закрепляет, что необходимо принимать во внимание «обязательства, налагаемые Европейской конвенцией о защите прав человека, и в частности ст. 5,6 , 13 и 14, а также соответствующие положения протоколов к ней, судебная практика Европейского суда по правам человека...»[18]. Таким образом, можно констатировать, что деятельность Комиссии опосредованно направлена на реализацию судебной практики ЕСПЧ в рамках судебных систем государств-членов, что предполагает существование некоторого уровня сотрудничества между наднациональным судебным органом и национальными органами (в том числе и судебными).

Наконец, стоит отметить, что деятельность комиссии ежегодно становится темой доклада ЕКЭП. Формирование данного доклада вменено в обязанность комиссии как Уставом (п. 6 ст. 7), так и Регламентом (ст. 11). Подготовка данного текста осуществляется как Бюро, так и Секретариатом комиссии и направляется в Комитет министров Совета Европы, в Парламентскую ассамблею Совета Европы. Более того, Регламент требует от президента ЕКЭП представления данного доклада Комитету министров в устной форме (п. 1 ст. 11). 
DOI: 10.7256/1811-9018.2014.12.14004

При цитировании этой статьи сноска на доі обязательна

\section{Право и политика $12(180) \cdot 2014$}

Библиография:

1. CEPEJ, Systmes Judiciaires Europens: Edition 2012, Council of Europe, 2012.

2. E. Desch, Preface, in European Judicial Systems 2002, Council of Europe Publishing

3. F. Benoît-Rohmer, H. Klebes, Le droit du Conseil de l'Europe: vers un espace juridique européen, Council of Europe, 2005.

4. J. Petaux, L'Europe de la démocratie et des droits de l'homme: l'action du Conseil de l'Europe, Council of Europe, 2009

5. Р.А. Гурбанов На днациональное право, его судебная га рантия на наднациональном уровне и интеграция во внутренние правопорядки как факторы стимулирования взаимодействия орга нов правосудия на европейском пространстве // Политика и Общество. - 2011. - 9. - С. 21 - 29.

6. Р. А. Гурбанов Правовые основы взаимодействия государств-членов Совета Европы в сфере правосудия // Политика и Общество. - 2011. - 8. - С. $9-14$.

7. Курбанов Р.А., Шведкова О.В., Белялова А.М. Аналитический обзор докладов и заключений, принятых на 99-й пленарной сессии Европейской комиссии за демократию через право (Венецианской комиссии) // Журнал зарубежного законодательства и сравнительного правоведения. - 2014. - 4. - С. $730-740$.

8. Р. А. Гурбанов Перспектива присоединения Европейского союза к Европейской конвенции о защите прав человека и основных свобод и влияние этого присоединения на отношения органов правосудия Европейского союза и Совета Европы // Политика и Общество. - 2011. - 7. - С. 109 - 118.

9. Р. А. Гурбанов Взаимодействие органов правосудия государств-членов ЕС с органами правосудия Европейского союза // Международное право и международные организации / International Law and International Organizations. - 2011. - 3. С. $128-143$.

10. Курбанов Р.А., Шведкова О.В., Белялова А.М. Аналитический обзор докладов и заключений, принятых на 97-й пленарной сессии Европейской комиссии за демократию через право // Журнал зарубежного законодательства и сравнительного правоведения. - 2013. - 6. - С. $1095-1103$.

11. Курбанов Р.А., Шведкова О.В., Белялова А.М. Аналитический обзор работы 98-й пленарной сессии Европейской комиссии за демократию через право (Венецианской комиссии Совета Европы) // Журнал зарубежного законодательства и сравнительного правоведения. - 2014. - 1. - С. 117 - 123.

12. Р. А. Гурбанов Европейская судебная сеть и Евроюст как основные субъекты сотрудничества органов правосудия государств-членов ЕС в сфере уголовного правосудия. // Международное право и международные организации / International Law and International Organizations. - 2011. - 4. - C. $113-120$.

\section{References (transliterated):}

1. E. Desch, Preface, in European Judicial Systems 2002, Council of Europe Publishing

2. F. Benoit-Rohmer, H. Klebes, Le droit du Conseil de l'Europe: vers un espace juridique européen, Council of Europe, 2005.

3. J. Petaux, L'Europe de la démocratie et des droits de l'homme: l'action du Conseil de l'Europe, Council of Europe, 2009

4. R.A. Gurbanov Na dnatsional'noe pravo, ego sudebnaya ga rantiya na nadnatsional'nom urovne i integratsiya vo vnutrennie pravoporyadki kak faktory stimulirovaniya vzaimodeistviya orga nov pravosudiya na evropeiskom prostranstve // Politika $\mathrm{i}$ Obshchestvo. - 2011. - 9. - C. $21-29$.

5. R. A. Gurbanov Pravovye osnovy vzaimodeistviya gosudarstv-chlenov Soveta Evropy v sfere pravosudiya // Politika i Obshchestvo. -2011. - 8. - C. 9 - 14 .

6. Kurbanov R.A., Shvedkova O.V., Belyalova A.M. Analiticheskii obzor dokladov i zaklyuchenii, prinyatykh na 99-i plenarnoi sessii Evropeiskoi komissii za demokratiyu cherez pravo (Venetsianskoi komissii) // Zhurnal zarubezhnogo zakonodatel'stva i sravnitel'nogo pravovedeniya. - 2014. - 4. - C. 730 - 740.

7. R. A. Gurbanov Perspektiva prisoedineniya Evropeiskogo soyuza k Evropeiskoi konventsii o zashchite prav cheloveka i osnovnykh svobod i vliyanie etogo prisoedineniya na otnosheniya organov pravosudiya Evropeiskogo soyuza i Soveta Evropy // Politika i Obshchestvo. - 2011. - 7. - C. $109-118$.

8. R. A. Gurbanov Vzaimodeistvie organov pravosudiya gosudarstv-chlenov ES s organami pravosudiya Evropeiskogo soyuza // Mezhdunarodnoe pravo i mezhdunarodnye organizatsii / International Law and International Organizations. - 2011. - 3. - C. 128 - 143.

9. Kurbanov R.A., Shvedkova O.V., Belyalova A.M. Analiticheskii obzor dokladov i zaklyuchenii, prinyatykh na 97-i plenarnoi sessii Evropeiskoi komissii za demokratiyu cherez pravo // Zhurnal zarubezhnogo zakonodatel'stva i sravnitel'nogo pravovedeniya. - 2013. - 6. - C. 1095 - 1103.

10. Kurbanov R.A., Shvedkova O.V., Belyalova A.M. Analiticheskii obzor raboty 98-i plenarnoi sessii Evropeiskoi komissii za demokratiyu cherez pravo (Venetsianskoi komissii Soveta Evropy) // Zhurnal zarubezhnogo zakonodatel'stva i sravnitel'nogo pravovedeniya. - 2014. - 1. - C. 117 - 123.

11. R. A. Gurbanov Evropeiskaya sudebnaya set' i Evroyust kak osnovnye sub"ekty sotrudnichestva organov pravosudiya gosudarstvchlenov ES v sfere ugolovnogo pravosudiya. // Mezhdunarodnoe pravo i mezhdunarodnye organizatsii / International Law and International Organizations. - 2011. - 4. - C. $113-120$. 